\title{
Nicotinamide Inhibition Properties for Copper Corrosion in 3.5\% NaCl Solution: Experimental and Theorical Investigations
}

\author{
Coulibaly Nagnonta Hippolyte ${ }^{1}$, Brou Yapi Serge ${ }^{1}$, Akpa Sagne ${ }^{2}$, Juan Creus ${ }^{3}$, Trokourey Albert ${ }^{1}$ \\ ${ }^{1}$ Laboratoire de Chimie Physique (LCP), Université Félix Houphouët-Boigny d'Abidjan, Abidjan, Côte d'Ivoire \\ ${ }^{2}$ Laboratoire de Chimie Organique et de Substances Naturelles (LCOSN), Université Félix Houphouët-Boigny d'Abidjan, \\ Abidjan, Côte d'Ivoire \\ ${ }^{3}$ Laboratoire des Sciences de l'Ingénieur pour l'Environnement (LaSIE), Université de La Rochelle, La Rochelle, France \\ Email: lesaintbys@yahoo.fr
}

How to cite this paper: Hippolyte, C.N., Serge, B.Y., Sagne, A., Creus, J. and Albert, T. (2018) Nicotinamide Inhibition Properties for Copper Corrosion in $3.5 \% \mathrm{NaCl}$ Solution: Experimental and Theorical Investigations. Journal of Materials Science and Chemical Engineering, 6, 100-121. https://doi.org/10.4236/msce.2018.63008

Received: February 14, 2018

Accepted: March 27, 2018

Published: March 30, 2018

Copyright $(0) 2018$ by authors and Scientific Research Publishing Inc. This work is licensed under the Creative Commons Attribution International License (CC BY 4.0).

http://creativecommons.org/licenses/by/4.0/

\begin{abstract}
This work reports the inhibition properties of nicotinamide (NAM) for copper protection during its applications in seawater systems such as water pipelines, shipbuilding, seawater desalination and heat exchange systems. The efficiency of NAM as a copper corrosion inhibitor in simulated seawater $(3.5 \%$ $\mathrm{NaCl}$ solution) was investigated by Tafel extrapolation and linear polarization methods in the temperature range from $20^{\circ} \mathrm{C}$ to $50^{\circ} \mathrm{C}$. The corrosion parameters and the adsorption isotherms were determined using potentiodynamic polarization techniques. It was found that the inhibition efficiency $(\eta)$ and the coverage rate $(\theta)$ increase up $80 \%$ at $25^{\circ} \mathrm{C}$ for nicotinamide concentration of $10 \mathrm{mM}$ but decrease as the temperature of the solution increases. Moreover, the obtained thermodynamic parameters using Langmuir model suggested a physical adsorption type. A correlation was found between the corrosion inhibition efficiency and the global theoretical parameters obtained by the functional density method B3LYP/ 6-31 + G (d, p). Local parameters such as condensed Fukui functions $[f(\boldsymbol{r})]$ and condensed local softness $[s(\boldsymbol{r})]$ indices have also been determined to obtain a chemical insight into atoms that have a significant tendency toward donation or acceptance of whole or fraction of electrons.
\end{abstract}

\section{Keywords}

Nicotinamide, Copper Corrosion Inhibition, Electrochemical Techniques

\section{Introduction}

Copper and its alloys have been found in a range of applications in seawater sys- 
tems such as water pipelines, shipbuilding, seawater desalination and heat exchange systems, due to the excellent electrical, thermal conductivity and mechanical properties [1] [2]. The high concentration of chlorides in seawater promotes various corrosion processes particulary at elevated temperatures [3]. To overcome this problem, the most commonly used inhibitors are organic molecules. Benzotriazole (BTA) and its derivates are the traditional inhibitors employed to protect the copper-based materials from corrosion [4] [5]. However, they have toxic effects to living organism and are harmful to the environment. Since environmental regulations are becoming more and more stringent regarding disposal and emission of toxic substances, application of chemical substances for corrosion inhibition is turning "green" too. Due to environmental concerns, vitamins are increasingly being considered as "green" corrosion inhibitors. Vitamins B2 (Riboflavin) [6], and C [7] have been used as steel inhibitors in various acid media. Vitamin $\mathrm{E}$ [8] was used for the protection of copper in an acid medium. Nicotinamide $\left(\mathrm{C}_{6} \mathrm{H}_{6} \mathrm{~N}_{2} \mathrm{O}\right)$, one of the two forms of vitamin $\mathrm{B}_{3}$ (Figure 1) was a promising substance because of its molecular structure with a pyridine ring and a functional group including an electron donor- $\mathrm{NH}_{2}$ group. Its water solubility is said to be good with respect to inhibitor application concentrations $(10 \mathrm{~g} / 100 \mathrm{~mL})$. These characteristics are considered to be important factors for a good inhibiton effects. In addition, nicotinamide is very cheap, readily available and most important, non-toxic.

Tunc Tuken et al., [9] and Florina Branzoi et al., [10] studied the effect of nicotinamide on iron corrosion in chloride solutions and inhibitive corrosion properties of nicotinamide on carbon steel in cooling water systems. Their results have shown that nicotinamide has no significant inhibition efficiency on the corrosion of the iron in neutral or alkaline conditions but had a good efficiency on carbon steel in coolind water system. Nicotinamide inhibits both anodic and cathodic reactions by adsorption on the carbon steel surface following the Langmuir adsorption isotherm. Such results have inspired us to test this molecule in the case of copper in seawater. A $3.5 \% \mathrm{NaCl}$ solution is frequently used for seawater simulation in laboratory. The objective of this work is to study the effects of nicotinamide on copper corrosion in a $3.5 \% \mathrm{NaCl}$ solution. The effect of inhibitor concentration, immersion time and temperature were also investigated. In addition to the used techniques (potentiodynamic polarization, linear polarization), quantum chemical calculations and surface analyzes of the tested samples were carried out.

\section{Materials and Methods of Analysis}

\subsection{Samples and Solutions}

The cylindrical samples of copper with a purity of $99.9 \%$ are mounted in glass tubes of suitable diameter to provide an exposed active geometrical surface area of $3.14 \mathrm{~cm}^{2}$ to the corrosive medium. Prior to each test, copper substrates were grinded with abrasive papers of decreasing particle size (400, 800, 1000, 1200 and 


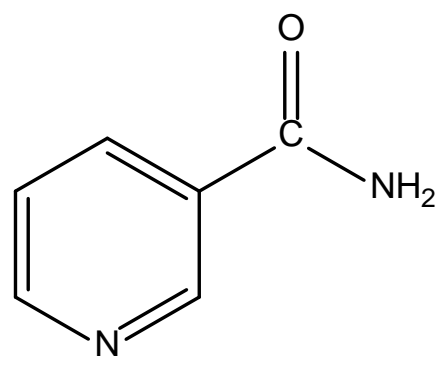

Figure 1. Molecular structure of nicotinamide (NAM).

2000), rinsed with Milli-Q water $(18.2 \mathrm{M} \Omega \cdot \mathrm{cm})$, degreased with ethanol and then rinsed again with Milli-Q water and dried in air.

The corrosive medium consists of a 3.5 weight \% sodium chloride solution which is obtained by dissolving Sigma-Aldrich sodium chloride (99.5\%) in deionized water. The analytical nicotinamide was purchased from Sisco Research Laboratories Pvt. Ltd and solutions of concentrations ranging from 1 to $11 \mathrm{mM}$ were prepared. All tests are carried out in aerated solution stirred with magnetic. A Thermo-cryostat Lauda model E100 permits to keep the electrolyte at fixed temperature.

\subsection{Electrochemical Measurements}

The electrochemical measurements were performed in a three-electrode cell with a volume of $0.5 \mathrm{~L}$. The working electrode (WE) was copper samples, the counterelectrode (CE) was a platinum wire and the reference (Ref) electrode was a saturated calomel electrode (SCE: $0.241 \mathrm{~V}$ vs SHE). The electrochemical study (Electrochemical impedance spectroscopy (EIS), potentiodynamictest and linear polarization) of the behavior of copper with contact to the corrosive medium without or with inhibitor is carried out using an experimental device composed of a Potentiostat-Galvanostat MODULAB, a DELL computer equipped with MODULAB XM ECS software allowing data processing. The potentiodynamic current-potential curves were recorded by varying the electrode potential automatically from -300 to $150 \mathrm{mV}$ from the OCP with a scanning rate of 0.2 $\mathrm{mV} \cdot \mathrm{s}^{-1}$. The polarization resistance measurements were performed by applying a controlled potential scan over a small range, typically $\pm 20 \mathrm{mV}$ with respect to $\mathrm{E}_{\text {corr }}$. The resulting current is linearly plotted versus potential; the slope of this plot at $\mathrm{E}_{\text {corr }}$ being the polarization resistance $(\mathrm{Rp})$.

\subsection{Surface Analysis}

\subsubsection{Raman Spectroscopy}

To gain insight into the corrosion inhibition mechanism of copper in $\mathrm{NaCl}$ environment by NAM, Raman spectroscopy measurements were performed using a Jobin Yvon Horiba high resolution spectrometer (LabRam HR8000 model) using a monochromatic He-Ne laser source of wavelength $\lambda=632.817 \mathrm{~nm}$. Spectrum processing is performed using JobinYvon's LabSpec software. 


\subsubsection{Optic Microscopy}

The morphology of the sample surface after immersion of $72 \mathrm{~h}$ in the $3.5 \% \mathrm{NaCl}$ solution with and without inhibitor was analyzed with a LEICA DM6000 M optical microscope equipped with LAS V4.9 software.

\subsection{Quantum Chemical Calculations}

The molecular structure and reactivity parameters of NAM, were calculated by DFT methods using B3LYP (Becke 3 parameters Lee Yang Parr) functional with the 6-31 + G (d,p) basic set for all atoms using Gaussian 03 program package [11]. The molecular structure of NAM molecules was built and visualized by Gauss View.

The electronic structure properties such as lowest unoccupied molecular orbital (LUMO), highest occupied molecular orbital (HOMO), energy gap $(\Delta \mathrm{E}$ $\left(\mathrm{E}_{\mathrm{LUMO}}-\mathrm{E}_{\text {Номо }}\right)$ ), ionization potential (I), electron affinity $(\mathrm{A})$, electronegativity $(\chi)$, molecular dipole moment $(\mu)$, global hardness $(\eta)$, softness $(\sigma)$, electron transfer fraction $(\Delta \mathrm{N})$ have been calculated.

\section{Results and Discussion}

\subsection{Open Circuit Potential}

The open circuit potential is the most immediately measurable electrochemical parameter. This simple technique provides preliminary informations on the nature of current processes at the metal/electrolyte interface: corrosion, passivation. Figure 2 presents the evolution of open circuit potential of the copper electrode in a $3.5 \% \mathrm{NaCl}$ solution with and without inhibitor.

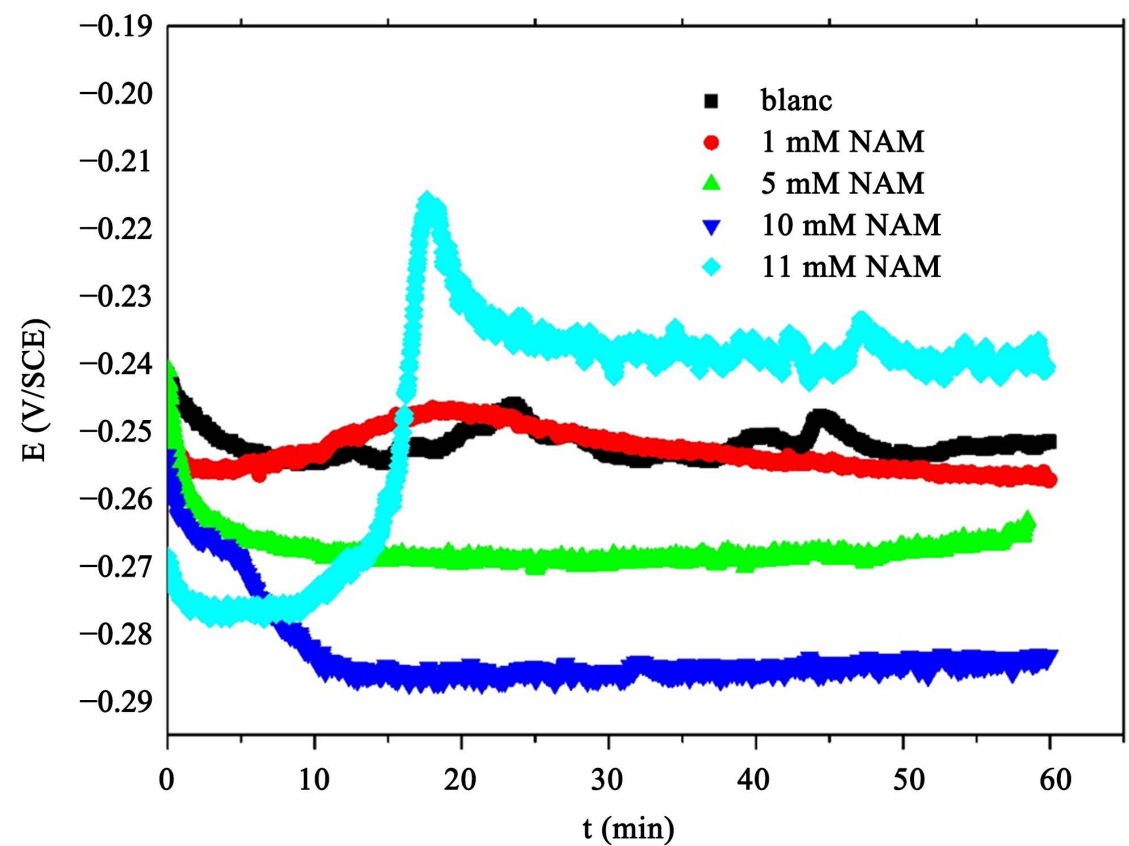

Figure 2. Open circuit potential-time curves for copper in $3.5 \% \mathrm{NaCl}$ solution without and with different NAM concentrations. 
In blank solution, the open circuit potential of the copper electrode slightly evolves from -220 to $-255 \mathrm{mV} / \mathrm{SCE}$ during the first hours of immersion due to the dissolution of copper and the formation of the corrosion product film. This latter film limits the dioxygen access towards the metallic interface that leads to a slight shift of the open circuit potential towards more negative values. We can observe some small potential fluctuations during the immersion that can be attributed to the evolution of the nature and/or surface coverage of the corrosion product film on the copper surface.

In presence of NAM, it is observed from the figure that in all studied systemethat OCP values start from a more positive value and decreases steadily before rising again to reacha steady state value. This rise in corrosion potential after the initial decrease is associated with the formation and thickening of the film at the copper surface, indicating the improvement of the corrosion resistance. For $1 \mathrm{mM}$ and $11 \mathrm{mM}$ concentrations, the corrosion potential increases up to 20 minutes and then decreases. This behavior can characterize a beginning of inhibition. For $11 \mathrm{mM}$ the OCP value increased dramatically at beginning indicating the formation of a very thick protective layer on copper surface. Nevertheless, the film formed at these concentrations would not be of a nature (composition or morphology) to protect the copper surface durably.

On the other hand, the displacement of the corrosion potential towards negative values is considered as an indicator of surface activation [12]. In chloride-containing media such as seawater, the decrease in the value of the open circuit potential is associated with the dissolution of the oxide native layer formed upon air exposure and the formation of $\mathrm{CuCl}$ complexes on the surface which does not adequately protect it [13].

Generally, the cathodic reaction on copper in the aerated $\mathrm{NaCl}$ solution is a reduction reaction of dioxygen according to the following Equations [14]:

$$
\mathrm{O}_{2}+2 \mathrm{H}_{2} \mathrm{O}+4 \mathrm{e}^{-} \rightarrow 4 \mathrm{OH}^{-}
$$

The process of anodic dissolution of copper in $\mathrm{NaCl}$ medium can be described by the following steps [14]:

$$
\begin{gathered}
\mathrm{Cu}+\mathrm{Cl}^{-} \rightarrow \mathrm{CuCl}+\mathrm{e}^{-} \\
\mathrm{CuCl}+\mathrm{Cl}^{-} \rightarrow \mathrm{CuCl}_{2}^{-} \\
\mathrm{CuCl}_{2}^{-} \rightarrow \mathrm{Cu}^{2+}+2 \mathrm{Cl}^{-}+\mathrm{e}^{-}
\end{gathered}
$$

Followed by the oxide formation:

$$
2 \mathrm{CuCl}_{2}^{-}+2 \mathrm{OH}^{-} \rightarrow \mathrm{Cu}_{2} \mathrm{O}+\mathrm{H}_{2} \mathrm{O}+4 \mathrm{Cl}^{-}
$$

The inhibitor addition leads to the evolution of the open circuit potential towards more positive values suggesting that the NAM protects the metal against corrosion by adsorption and the formation of a protective layer on its surface.

\subsection{Potentiodynamic Polarization Curves}

Figure 3 shows the polarization curves of the copper in an aerated $3.5 \% \mathrm{NaCl}$ 


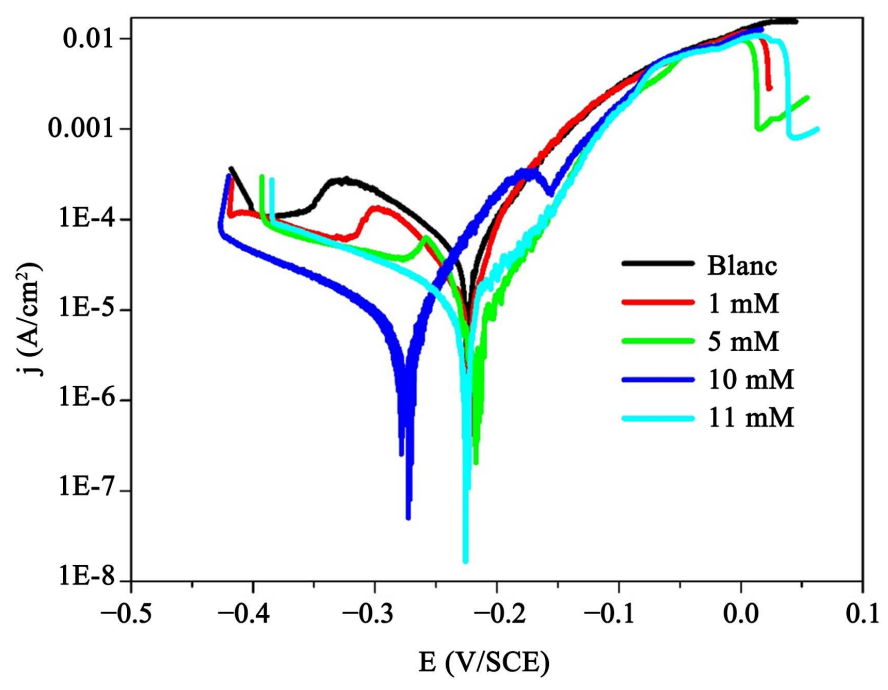

Figure 3. Potentiodynamic polarization curves for copper in $3.5 \%$ $\mathrm{NaCl}$ solution without and with NAM at different concentrations.

solution without and with addition of the NAM at different concentrations. The polarization curves were plotted after one hour of immersion in saline solution.

In the blank solution, the corrosion potential is around $-220 \mathrm{mV} / \mathrm{SCE}$. In the cathodic domain, it can be observed a first regime up to $-340 \mathrm{mV} / \mathrm{SCE}$ where a linear variation of the current density versus potential is noticed. This evolution corresponds to the dioxygen reduction reaction on the copper surface. For higher cathodic overpotentials, a reduction peak is observed, this could be associated to the reduction of the copper oxides that were formed during the immersion period. A linear variation of the current density versus potential is observed in the anodic domain. With the addition of inhibitor, the shape of the polarization curves is quite similar.

An increase in NAM concentration leads to a shift of the corrosion potential towards more cathodic potentials for $10 \mathrm{mM}$ and no significant displacement for other concentrations. We can also observe a remarkable drop of the current density for $10 \mathrm{mM}$ compared to that obtained in a blank solution with a modification of the cathodic Tafel slope values.

The anodic polarization curves are not drastically affected by the presence of the NAM nevertheless it can be noted slight anodic current drops for 5 and 11 $\mathrm{mM}$. The blank and $1 \mathrm{mM}$ curves are confounded, this indicates that the adsorbed molecules of NAM at that concentration have no effect on the mechanism of copper dissolution. A slight modification of the anodic slope is observed with the presence of the inhibitor species. The electrochemical features suggest a mixed type character of this inhibitor [15]. The Electrochemical parameters such as corrosion potential $\left(E_{c o r r}\right)$, anodic $\left(b_{a}\right)$, and cathodic $\left(b_{c}\right)$ Tafel slopes and the corrosion current density $\left(j_{c o r r}\right)$ were determined by Tafel extrapolation method on the potentiodynamic polarization curves. The values are gathered in Table 1. The current density was used to calculate the copper corrosion rate (CR) and the inhibitor efficiency $(\eta)$ using the Equations (6) and (7): 
Table 1. Electrochemical parameters and inhibition efficiency of NAM for copper in $3.5 \% \mathrm{NaCl}$ solution.

\begin{tabular}{cccccccc}
\hline $\begin{array}{c}\text { Concentration } \\
(\mathrm{mM})\end{array}$ & $\begin{array}{c}E_{\text {corr }} \\
(\mathrm{V} / \mathrm{SCE})\end{array}$ & $\begin{array}{c}j_{\text {corr }} \\
\left(\mu \mathrm{A} \cdot \mathrm{cm}^{-2}\right)\end{array}$ & $\begin{array}{c}b_{a} \\
(\mathrm{mV} / \mathrm{dec})\end{array}$ & $\begin{array}{c}-b_{c} \\
(\mathrm{mV} / \mathrm{dec})\end{array}$ & $\begin{array}{c}C R \\
(\mathrm{~mm} / \mathrm{an})\end{array}$ & $\begin{array}{c}R_{p} \\
\left(\Omega \cdot \mathrm{cm}^{2}\right)\end{array}$ & $\begin{array}{c}\eta \\
(\%)\end{array}$ \\
\hline 0 & -224 & 46.5 & 48 & 94 & 0.544 & 336.6 & - \\
1 & -224 & 14.6 & 48 & 56 & 0.173 & 2381.1 & 68 \\
5 & -217 & 11.2 & 57 & 56 & 0.131 & 3438.7 & 76 \\
10 & -274 & 9.0 & 55 & 186 & 0.105 & 6431.0 & 80 \\
11 & -223 & 13.6 & 60 & 212 & 0.159 & 4688.0 & 71 \\
\hline
\end{tabular}

$$
\begin{gathered}
C R(\mathrm{~mm} / \mathrm{an})=\frac{3.280 \times j_{\text {corr }} \times M_{\mathrm{Cu}}}{n \times \rho_{\mathrm{Cu}}} \\
\eta=\frac{j_{\text {corr }}-j_{\text {corr }}^{\text {inh }}}{j_{\text {corr }}} \times 100
\end{gathered}
$$

$j_{\text {corr }}$ et $j_{\text {corr }}^{\text {inh }}\left(\mathrm{mA} / \mathrm{cm}^{2}\right)$ are the corrosion current densities of the copper after immersion in $3.5 \% \mathrm{NaCl}$ medium without and with addition of inhibitor respectively. $M_{\mathrm{Cu}}(\mathrm{g} / \mathrm{mol})$ is the molar mass of copper, $\rho_{\mathrm{Cu}}\left(\mathrm{g} / \mathrm{cm}^{3}\right)$ the copper density and $\mathrm{n}$ is the number of exchanged electrons during the oxidation. The polarization resistance was calculated from the Stern-Geary Equation:

$$
R_{P}=\frac{b_{a} \times b_{c}}{2.303\left(b_{a}+b_{c}\right) j_{\text {corr }}}
$$

$b_{a}$ and $b_{c}$ are the Tafel slopes.

From the results obtained in Table 1, we can conclude that the polarization resistance and the inhibitory efficiency of NAM increase with the concentration of inhibitor and reach respectively maximum values of $6431 \Omega$ and $80 \%$ for a inhibitor concentration of $10 \mathrm{mM}$ and decrease thereafter. L. Elhousni et al., [16]. have reported a similar behaviour in their work on copper in the cooling liquids of industrial systems in the presence of Cetyltrimethyl Ammonium Bromide (CTAB). These authors have justified the decrease of the efficiency in the case of high inhibitor concentrations by the formation of an oxide and/or hydroxide layer on the surface of the material.

Others authors [17] attribute this behavior to an adsorbed layer saturation and to the formation of micelles which should decrease the number of transported inhibitory molecules on the metal surface, thus causing a decrease in the inhibition efficiency. The Tafel cathode slope $\left(b_{c}\right)$ drastically changes with inhibitor addition while the anodic Tafel slope $\left(b_{a}\right)$ variation is very small, thus indicating that the NAM changesonly the dioxygen reduction mechanisms. It is widely believed that a compound could be recognized as an anodic or cathodic inhibitor if the corrosion potential variation is greater than $85 \mathrm{mV}$ [18]. In our study, the largest displacement of $E_{\text {corr }}$ was about $50 \mathrm{mV}$ toward cathodic direction. Based on these results, NAM is considered as mixed-type inhibitors for copper in the $3.5 \% \mathrm{NaCl}$ solution. 


\subsection{Long-Term Immersion Measurements}

The concentration of $10 \mathrm{mM}$ seems to be the optimal concentration of NAM accordind to the potentiodynamic polarization study. Long-term immersion measurements at the open circuit potential were performed and polarization resistance test was also scheduled in order to follow the dissolution kinetic. In Figure 4 it is possible to observe the polarization resistance of copper as a function of time in the corrosive solution without and with $10 \mathrm{mM}$ of NAM.

Figure 4 presents the evolution of the polarization resistance during the extended immersion test. Without inhibitor, the polarization resistance increases up to 25 hours. This increase suggests the ennoblement of the metal. After $25 \mathrm{~h}$ of immersion, an important decrease of the $R_{p}$ is observed and maybe associated to a change in the nature of the corrosion product film during the immersion. With inhibitor, after the two first hours a continuous decrease of polarization resistance is observed during the immersion time. It is found that the inhibition efficiency of the inhibitor $(10 \mathrm{mM})$ decreases with increasing immersion time. This effect can be due to desorption of inhibitor molecule with immersion time [10] [19].

\subsection{Adsorption Isotherm Studies}

It is generally accepted that organic inhibitor inhibits metal corrosion by getting adsorb on the surface and the process is mere substitution in which water molecules on the metal surface are replaced by inhibitor molecules [20]. Thus, useful information on metal corrosion inhibition by an organic inhibitor can be obtained by employing adsorption isotherms. Experimental data obtained from PDP measurements for the corrosion inhibition of copper in $\mathrm{NaCl} 3.5 \%$ solution by NAM were fitted into various adsorption isotherms including Langmuir, Temkin, El-Awady thermodynamic, Frumkin, and Frundlich adsorption isotherms. By far, the best fit is obtained for Langmuir adsorption isotherm. Langmuir adsorption isotherm is defined according to the following equation [20]:

$$
\frac{C_{i n h}}{\theta}=\frac{1}{K_{a d s}}+C_{i n h}
$$

The curve of $C_{i n h} / \theta$ as a function of the $C_{i n h}$ (inhibitor concentration) is shown in Figure 5.

However, there is a slight deviation from the value of the slope of the unit (Table 2). Therefore, the corrected Langmuir model is more suitable for NAM compound adsorption. The deviation of the value of the slope to unit is due to the interactions between the adsorbed species on the metal surface. The modified Langmuir model takes into account the interactions between the adsorbed species. The modified Langmuir equation is as follow [21]:

$$
\frac{C_{i n h}}{\theta}=\frac{n}{K_{a d s}^{\prime}}+n C_{i n h}
$$

where $n$ is the slope of the straight line corresponding to the Langmuir isotherm. 


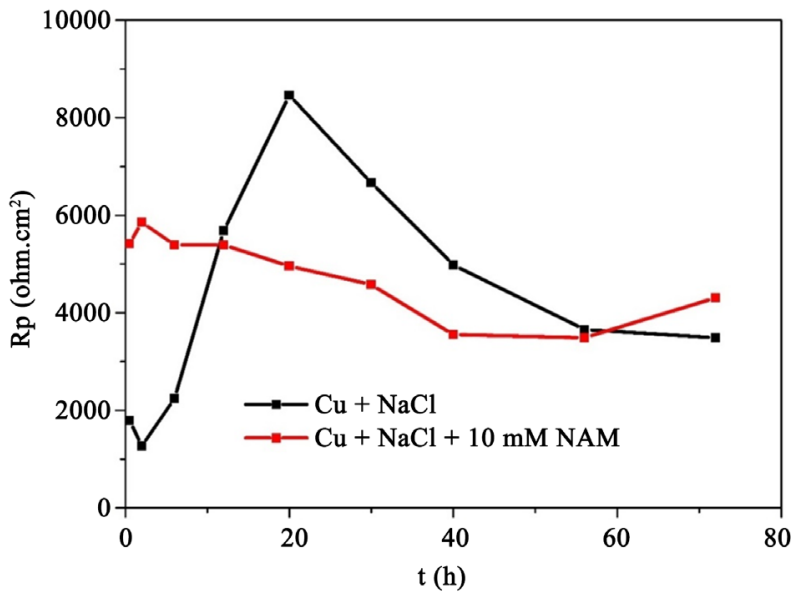

Figure 4. Evolution of polarization resistance with time, during the immersion in aggressive solution: without and with $10 \mathrm{mM}$ of NAM.

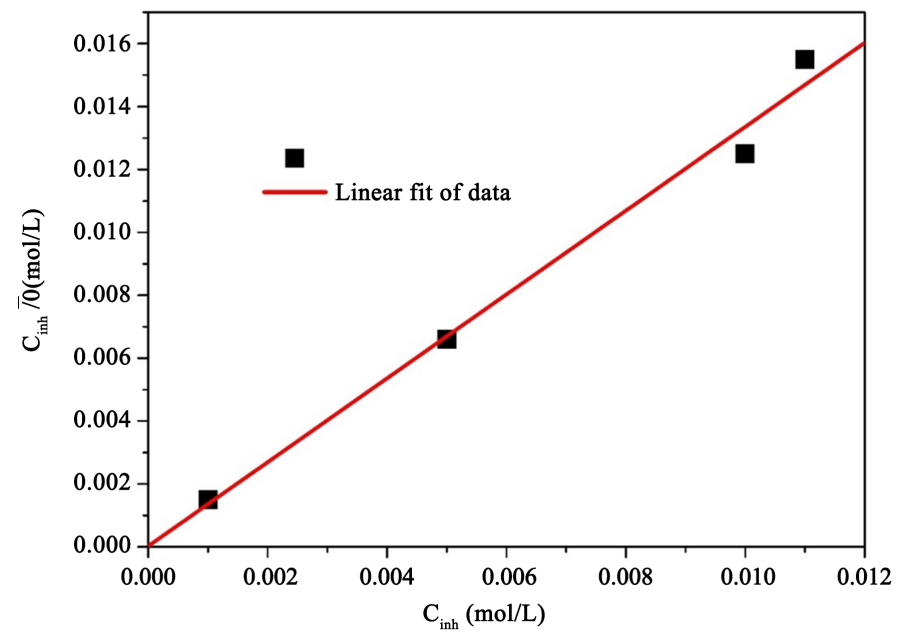

Figure 5. Langmuir adsorption isotherms of NAM on the copper surface in $3.5 \% \mathrm{NaCl}$ solution at $298 \mathrm{~K}$.

Table 2. The adsorption parameters of NAM on copper in $3.5 \% \mathrm{NaCl}$.

\begin{tabular}{cccc}
\hline$K_{\text {ads }}\left(10^{4} \mathrm{M}^{-1}\right)$ & $\Delta G_{\text {ads }}^{0}\left(\mathrm{~kJ} \cdot \mathrm{mol}^{-1}\right)$ & $R^{2}$ & $n$ \\
\hline 4 & -36.20 & 0.9938 & 1.3332 \\
\hline
\end{tabular}

$\theta=\frac{j_{\text {corr }}-j_{\text {corr (inh) }}}{j_{\text {corr }}}$ is the coverage rate and $K_{a d s}$ is the equilibrium constant of the adsorption process related to the free enthalpy of adsorption by the Equation (11) [22]:

$$
\Delta G_{a d s}^{0}=-R T \ln 55.5 K_{a d s}
$$

The estimated values of $K_{a d s}$ and $\Delta G_{a d s}^{0}$ have been recorded in Table 2.

These $K_{a d s}$ value is higher. This high value indicates that the adsorbed layer on the copper surface is stable [23]. It is reported in the literature [24] that val- 
ues of $\Delta G_{\text {ads }}^{0}$ greater than $-20 \mathrm{~kJ} \cdot \mathrm{mol}^{-1}$ are generally related to interactions between charged molecules and metal charges (physisorption). On the other hand, the values less than $-40 \mathrm{~kJ} \cdot \mathrm{mol}^{-1}$ is attributed to a transfer of charges between the molecules of the inhibitor and the metal surface (chemisorption) with the formation of covalent or coordination bonds. In the present work, the value of $\Delta G_{a d s}^{0}=-36.20 \mathrm{~kJ} \cdot \mathrm{mol}^{-1}$ suggested that the adsorption of NAM on copper surface involve physical as well as chemical adsorption.

\subsection{Effect of Temperature}

Temperature is one of the factors that can modify the behavior of materials in a given corrosive medium as well as the inhibitory efficiency of a compound. Considering the importance of this factor, we have carried out potentiodynamic polarization tests of copper in the $3.5 \% \mathrm{NaCl}$ study medium without and with addition of $10 \mathrm{mM}$ of inhibitor in a temperature varying from $20^{\circ} \mathrm{C}$ to $50^{\circ} \mathrm{C}$. The obtained curves are shown in Figure 6 . The $E_{\text {corr }}$ and $j_{\text {corr }}$ values obtained from these curves are shown in Table 3.

According to the Figure 6, the increase in temperature leads to an increase in the current density both without and with inhibitor. The decrease in inhibition efficiency with increasing temperature as observed in Table 3 is suggestive of physisorption mechanism generally attributed to electrostatic interaction between charged molecules and charged metal. The decrease in inhibition efficiencies might be due to the weakening of adsorbed inhibitor film on the copper surface. According to Obot et al., as temperature increases, Gibbs free energy and change in enthalpy rise to a higher value, so that some of the chemical bonds joining the molecules onto the metallic surface are impaired and the film stability reduced. It may further be attributed to a possible shift of the adsorption/desorption equilibrium towards desorption of adsorbed inhibitor due to increasing solution agitation. Thus, as the temperature increases the number of adsorbed molecules decreases, leading to a decrease in the inhibition efficiency [25].

Table 3. Electrochemical parameters of the corrosion of copper in $\mathrm{NaCl} 3.5 \%$ solution without and with $10 \mathrm{mM}$ of inhibitor.

\begin{tabular}{ccccc}
\hline Solution & Temperatures $(\mathrm{K})$ & $E_{\text {corr }}(\mathrm{V} / \mathrm{SCE})$ & $j_{\text {corr }}\left(\mu \mathrm{A} / \mathrm{cm}^{2}\right)$ & EI (\%) \\
\hline \multirow{3}{*}{ Blank } & 303 & -225 & 46.8 & - \\
& 313 & -260 & 92.2 & - \\
& 323 & -271 & 122.0 & - \\
& 293 & -269 & 498.0 & - \\
10 mM NAM & 303 & -239 & 9.0 & 80.76 \\
& 313 & -234 & 20.1 & 78.20 \\
& 323 & -241 & 37.0 & 70.40 \\
\hline
\end{tabular}




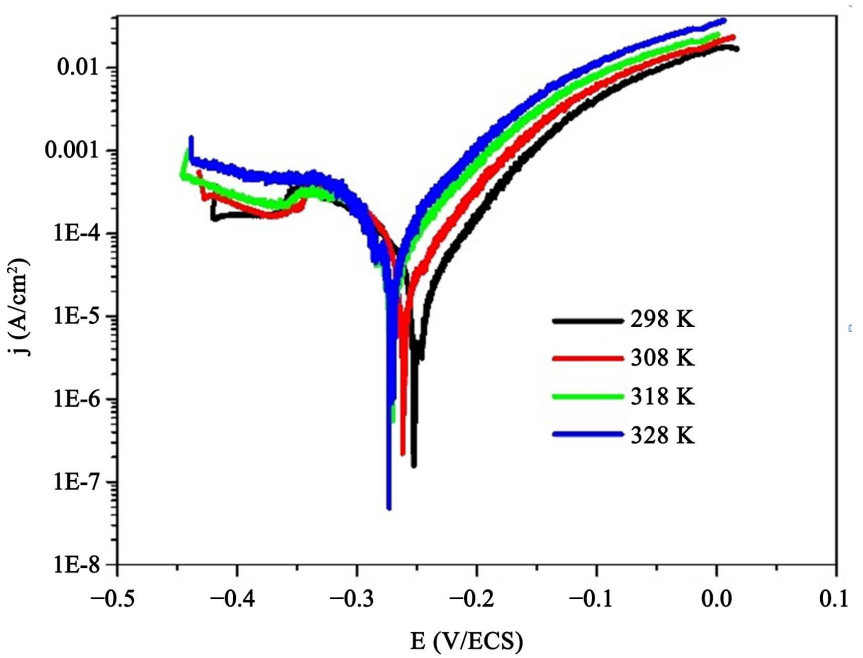

(a)

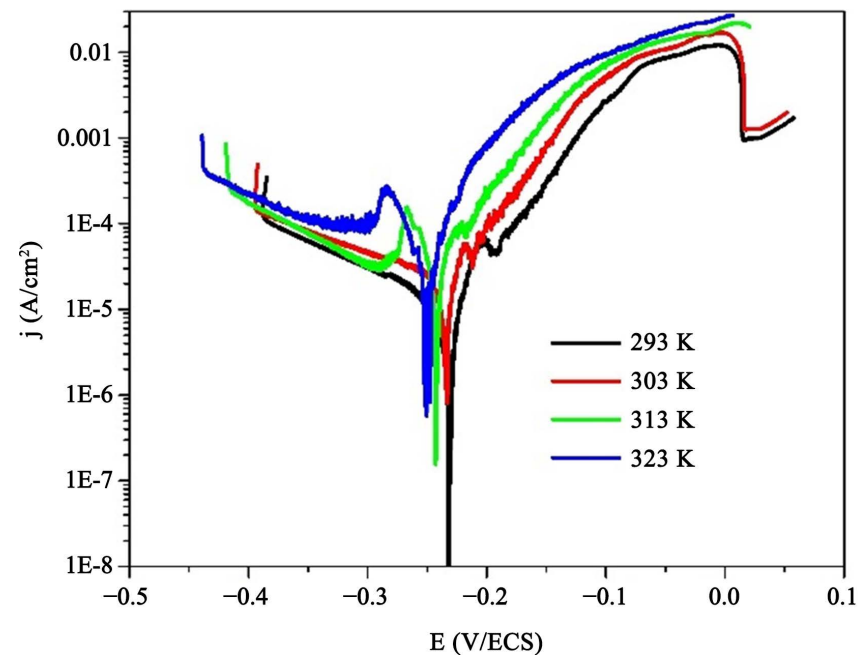

(b)

Figure 6. Polarization curves of copper in $\mathrm{NaCl} 3.5 \%$ solution without inhibitor (a) and with $10 \mathrm{mM}$ of NAM (b) at different temperatures after $1 \mathrm{~h}$ immersion.

We also note that the study of the effect of temperature can inform us about the type of adsorption of the inhibitor on the surface of the metal (chemisorption or physisorption) by the determination of the activation energy $\left(E_{a}\right)$, the enthalpy $\left(\Delta H_{a}\right)$ and entropy $\left(\Delta S_{a}\right)$ of activation of the corrosion process. The dependence of corrosion current density at temperature can be expressed by Arrhenius Equation (12) and transition state Equation (13):

$$
\begin{gathered}
j_{\text {corr }}=A \exp \left(-\frac{E_{a}}{R T}\right) \\
\log \left(\frac{j_{\text {corr }}}{T}\right)=\left[\log \left(\frac{R}{\mathrm{~N} h}\right)+\frac{\Delta S_{a}}{2.303 R}\right]-\frac{\Delta H_{a}}{2.303 R T}
\end{gathered}
$$

where $E_{a}$ is the apparent effective activation energyR $\left(\mathrm{J} \cdot \mathrm{mol}^{-1} \mathrm{~K}^{-1}\right)$ is the perfect gas constant, h (J.s) the Planck constant, $\mathrm{T}(\mathrm{K})$ the absolute temperature, $\mathrm{N}$ 
$\left(\mathrm{mol}^{-1}\right)$ the number of Avogadro and A the pre-exponential factor of Arrhenius.

Figure 7 shows the plots $\ln j_{\text {corr }}=f\left(\frac{1000}{T}\right)$ and $\log \left(\frac{j_{\text {corr }}}{T}\right)=f\left(\frac{1000}{T}\right)$. The activation parameters recorded in Table 4 were determined.

In our investigations, the activation energy found in presence of NAM is higher than that obtained without this molecule, so the adsorption of the studied molecule onto the copper surface is found to be physical in nature [26]. The positive sign $\Delta H_{a}$ shows the endothermic nature of the copper dissolution process. The increase in the enthalpy value after the addition of NAM indicates that in the presence of inhibitory molecules, the dissolution of the metal is more difficult [27]. For the negative sign of the activation entropy both in the solution with and without an inhibitor, it can be attributed to the disorder created by the inhibitory molecules on the surface of the metal .The adsorption of adsorbate on the metal surface is regarded as a substitutional adsorption process between the organic compound in the aqueous phase and water molecule adsorbed on the metal surface [20]. The adsorption of inhibitors on the copper surface would be in equilibrium with the desorption of surface water molecules:

$$
\operatorname{Org}_{(\text {sol })}+n \mathrm{H}_{2} \mathrm{O}_{(\text {ads })} \rightarrow \operatorname{Org}_{(\text {ads })}+n \mathrm{H}_{2} \mathrm{O}_{(\text {sol })}
$$

where $\operatorname{Org}_{(\text {sol })}$ and $\operatorname{Org}_{(a d s)}$ are the adsorbates in the bulk solution and adsorbed on the surface respectively; $\mathrm{H}_{2} \mathrm{O}_{(a d s)}$ and $\mathrm{H}_{2} \mathrm{O}_{(\text {sol })}$ are water molecules adsorbed on the surface and in the solution respectively.

Table 4. Copper dissolution activation parameters in $3.5 \% \mathrm{NaCl}$ without and with NAM (10 M).

\begin{tabular}{ccccc}
\hline Solution & $\mathrm{A}\left(\mu \mathrm{A} / \mathrm{cm}^{2}\right)$ & $\mathrm{E}_{\mathrm{a}}\left(\mathrm{kJ} \cdot \mathrm{mol}^{-1}\right)$ & $\Delta \mathrm{H}_{\mathrm{a}}\left(\mathrm{kJ} \cdot \mathrm{mol}^{-1}\right)$ & $\Delta \mathrm{S}_{\mathrm{a}}\left(\mathrm{J} \cdot \mathrm{mol}^{-1} \mathrm{~K}^{-1}\right)$ \\
\hline Blank & $3.54 \times 10^{6}$ & 61.27 & 58.60 & -129.21 \\
$10 \mathrm{mMNAM}$ & $7.36 \times 10^{6}$ & 84.38 & 81.75 & -64.90 \\
\hline
\end{tabular}
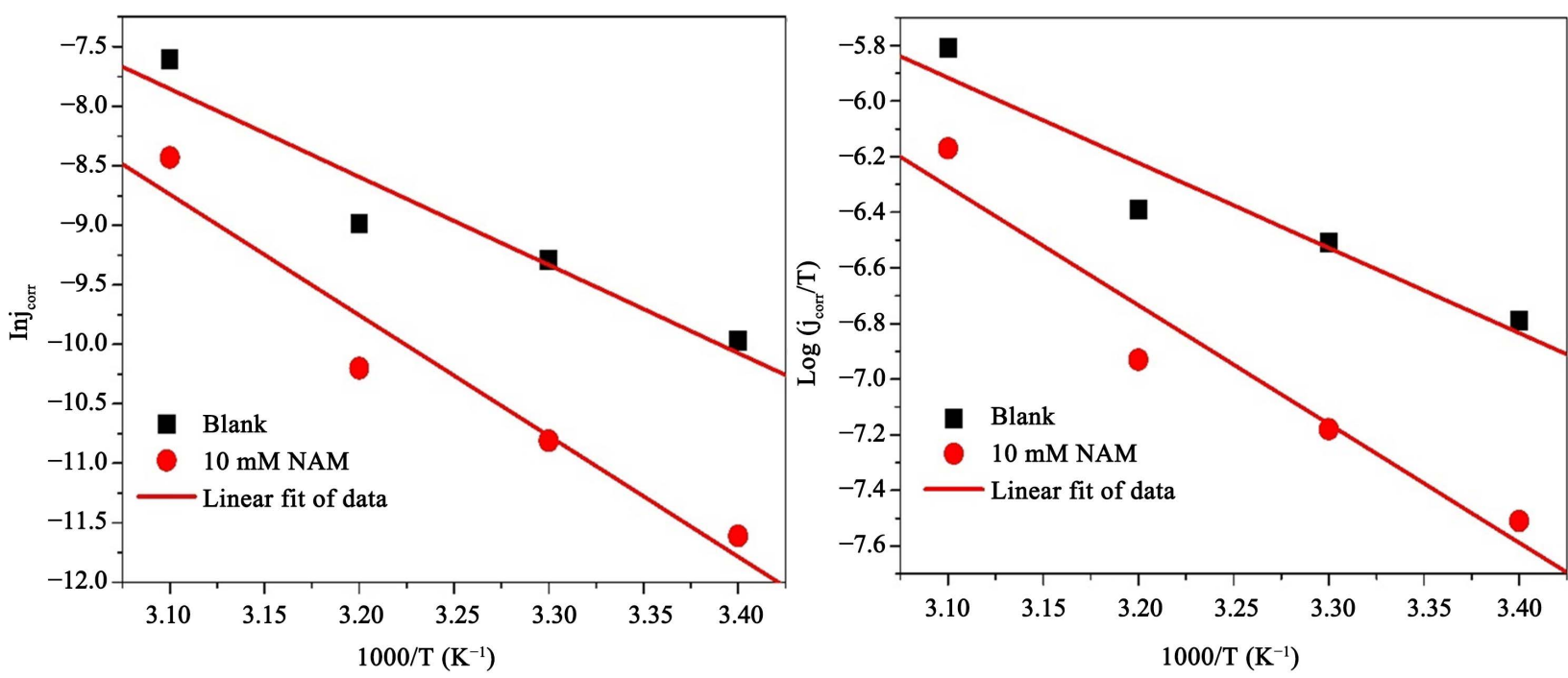

Figure 7. Arrhenius plot of $\operatorname{Ln}\left(j_{\text {corr }}\right)$ and Transition state plot of $\log \left(j_{\text {corr }} / \mathrm{T}\right)$ versus $1000 / \mathrm{T}$ for copper corrosion in $\mathrm{NaCl} 3.5 \%$ in the absence and presence of $10 \mathrm{mM}$ of NAM. 


\subsection{Surface Analysis}

\subsubsection{Raman Spectroscopy}

The surface of specimens exposed to $\mathrm{NaCl} 3.5 \%$ solution with $10 \mathrm{mM}$ of NAM for 72 hours were examined using Raman spectroscopy. To help to interpret the obtained spectra of $\mathrm{Cu}-\mathrm{NAM}$ system, raman spectra of pure NAM powder was also recorded. The two raman spectra are shown in Figure 8. Some Raman mode assignment found are listed in Table 5 [28] [29] [30]. We can note the shift to lower frequencies in the ring breathing and ring stretching modes; 1045 to 1034 and 1580 to 1530 respectively. According to Soliman et al. this can be due to the coordination of metal ion through the pyridine nitrogen of NAM [31]. It is observed that the strong $\mathrm{C}=\mathrm{O}$ stretching peak at $1680 \mathrm{~cm}^{-1}$ disappeared completely in the Cu-NAM spectrum, indicating the involvement of oxygen heteroatom present in NAM in the adsorption process.

The ring $\mathrm{N}$ pyridine nuclei, $\mathrm{NH}_{\text {2wagging }}$ Raman mode increase their vibrational frequencies; 834 to $845 \mathrm{~cm}^{-1}$ and 389 to $400 \mathrm{~cm}^{-1}$ respectively. In addition, the two spectra are very similar in their spectral features but the one from the NAM powder is better resolved. All these observations reveal that NAM molecules inhibit the corrosion of copper by strong adsorption onto the surface, forming a Cu-NAM complex.

Table 5. Raman absorption frequencies for the free inhibitor and adsorbed inhibitor on copper surface.

\begin{tabular}{|c|c|c|}
\hline $\begin{array}{l}\text { NAM powder } \\
\left(\mathrm{cm}^{-1}\right)\end{array}$ & $\begin{array}{l}\text { Sample NAM-Cu } \\
\quad\left(\mathrm{cm}^{-1}\right)\end{array}$ & Tentative assignement \\
\hline 1680 & - & $v(\mathrm{C}=\mathrm{O})$ \\
\hline 1617 & 1599 & $\mathrm{NH}_{2 \text { scis }}$ \\
\hline 1599 & 1581 & $v(\mathrm{C}=\mathrm{C})_{\text {ring }}, v(\mathrm{C}=\mathrm{N})_{\text {ring }}$ \\
\hline 1581 & 1530 & $v_{\text {ring }}$ \\
\hline 1391 & 1406 & $v_{\mathrm{CNamide}}+\delta(\mathrm{CCH})$ \\
\hline 1161 & 1198 & $v_{\text {ring }}+\delta(\mathrm{CCH})$ \\
\hline 1125 & - & $\delta(\mathrm{CH})$ \\
\hline 1096 & - & $\mathrm{NH}_{2 \text { rock }}$ \\
\hline 1045 & 1034 & Pyridine ring breathing \\
\hline 943 & - & $\gamma(\mathrm{CH}), \mathrm{C}-\mathrm{NH}_{2}$ \\
\hline 834 & 845 & ring $\mathrm{N}$ in pyridine nuclei \\
\hline 790 & 797 & $\delta_{\text {ring }}$ \\
\hline 648 & 661 & $\gamma_{\text {ring }}$ \\
\hline 630 & 644 & $\delta_{\text {ring }}$ \\
\hline 389 & 400 & $\mathrm{NH}_{2 \text { wagging }}$ \\
\hline
\end{tabular}




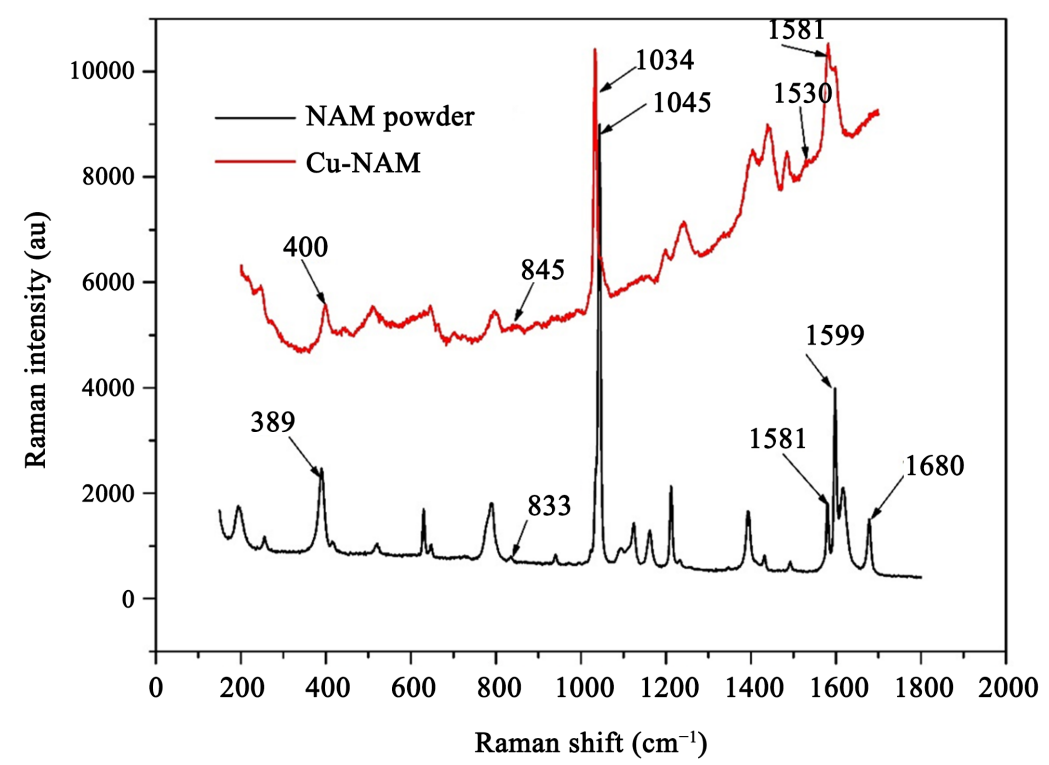

Figure 8. Raman spectra of NAM powder and copper in $3.5 \% \mathrm{NaCl}$ with 10 $\mathrm{mM}$ of NAM after 72 hours of immersion.

\subsubsection{Optic Microscopy}

Figure 9 shows the picture of the copper samples after immersion in a 3.5\% $\mathrm{NaCl}$ solution for $72 \mathrm{~h}$ at $298 \mathrm{~K}$ in the absence and presence of $10 \mathrm{mM}$ of inhibitor. (Figure 9(a)) presents the fresh grinded sample with grinded scratches on it surface. The surface of the sample in the absence of the inhibitor (Figure 9(b)) is strongly corroded. No scratches were observed on the surface of the sample in blank solution as the numerous corrosion products were deposited on the copper surface. A pitting corrosion occurred on surface of copper immersed in the solution with NAM (Figure 9(c)) inhibitor however the grinded scratches are always visible on the copper surface. Evidently the amount of corrosion products in the blank solution is very large than that with NAM, which suggests that corrosion rate was effectively reduced by the presence of the inhibitor. The comparison of these three figures reveals a marked inhibiting efficiency of NAM.

\subsection{Quantum Chemical Calculations}

Quantum chemical calculations were carried out to study the mechanism of adsorption and inhibition of the molecule studied in functional theory of density by the hybrid functional B3LYP (Becke 3 parameters Lee Yang Parr) with the base of orbitals 6-31 + G (d, p) using the Gaussian 03 W software.

\subsubsection{Global Parameters}

This theoretical study of the nicotinamide molecule has been carried out with a view to highlighting the factors which may favor its inhibitory nature. The calculated chemical parameters include the energy of the highest occupied $\left(\mathrm{E}_{\text {номо }}\right)$ and lowest unoccupied ( $\mathrm{E}_{\mathrm{LUMO}}$ ) molecular orbital, the difference $\Delta \mathrm{E}=\mathrm{E}_{\mathrm{LUMO}}-$ $\mathrm{E}_{\text {номо }}$, the dipole moment $(\mu)$ and the charges of Mulliken on heteroatoms. Parameters such as ionization potential (I), electronic affinity (A), electronegativity 

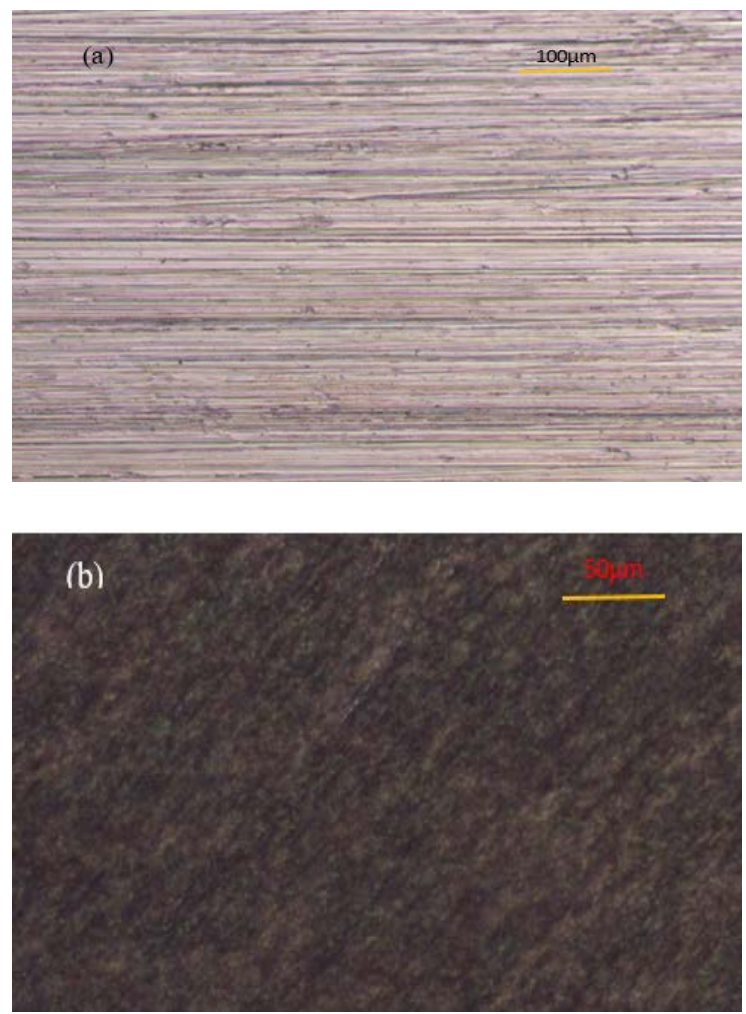

\section{(c)}

\section{0 um}

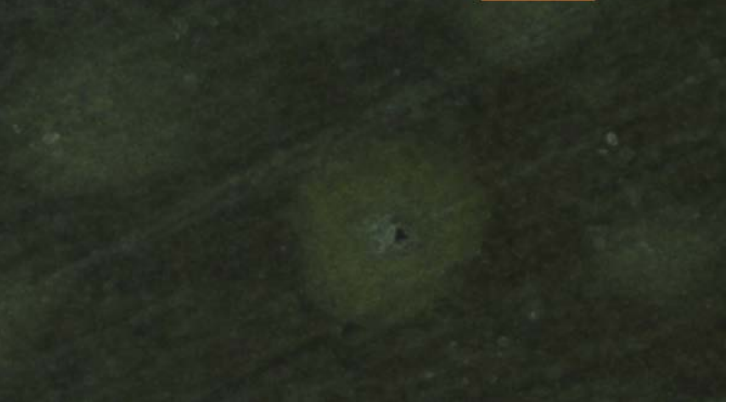

Figure 9. Pictures of the copper surface: (a) Freshly polished; (b) After immersion in blank solution; (c) After immersion ( $t=72$ hours) in solution with $10 \mathrm{mM}$ of NAM.

$(\chi)$, global hardness $(\eta)$, global softness $(S)$, global electrophilicity index $(w)$, fraction of transferred electrons $(\Delta N)$ and total energy change $\left(\Delta \mathrm{E}_{\mathrm{T}}\right)$ were also calculated using the following relationships [32]:

$$
\begin{aligned}
I & =-E_{\text {Номо }} \\
A & =-E_{\text {LUмО }} \\
\chi & =\frac{1}{2}(I+A) \\
\eta & =\frac{1}{2}(I-A)
\end{aligned}
$$




$$
\begin{gathered}
S=\frac{1}{\eta}=\frac{2}{I-A} \\
w=\frac{\mu_{p}^{2}}{2 \eta}=\frac{\chi^{2}}{2 \eta} \\
\Delta N=\frac{\chi_{\mathrm{Cu}}-\chi_{i n h}}{2\left(\eta_{\mathrm{Cu}}+\eta_{\text {inh }}\right)} \\
\Delta E_{T}=-\frac{\eta}{4}
\end{gathered}
$$

where $\chi_{\mathrm{Cu}}$ and $\chi_{\text {inh }}$ denote respectively the absolute electronegativity of copper and the inhibitor, $\eta_{\mathrm{Cu}}$ and $\eta_{\text {inh }}$ are respectively the global hardness of copper and the inhibitor. In this work $\Delta N$ has been determined using $\chi_{\mathrm{Cu}}=$ $4.48 \mathrm{eV}$ and $\eta_{\mathrm{Cu}}=0$ [33].

Figure 10 shows the Optimized molecular structure (left) and mulliken charge distribution (right) of nicotinamide (NAM) molecule obtained with DFT at the B3LYP/6-31 + G (d, p) level of theory in water solution phase. There is a general consensus by several authors that the more negatively charged an atom is the more it can be adsorbed on the metal surface through donor-acceptor type reaction [34] [35]. It can therefore be easily seen that the oxygen, nitrogen and carbon atoms of the Pyridine ringcarry a high density of negative charges and could therefore constitute active adsorption sites.

Analyzing HOMO-LUMO diagrams (Figure 11), we can observe that HOMO and LUMO densities are concentrated in nearly the same region, around the
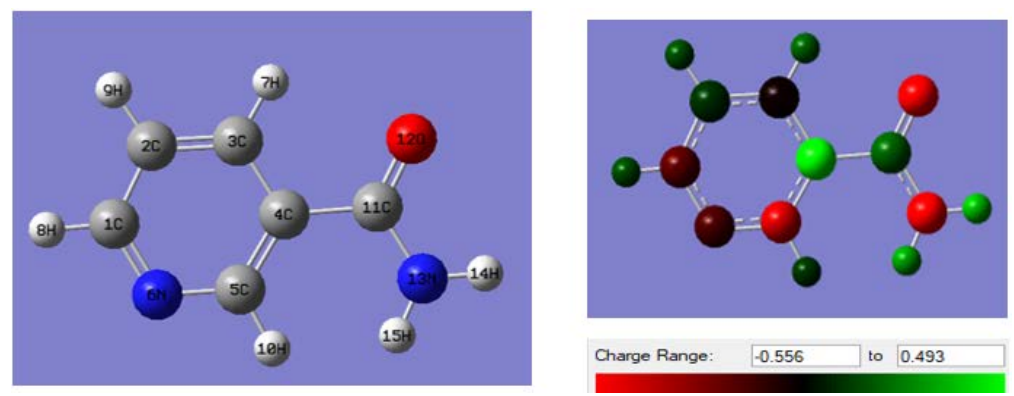

Figure 10. Optimized molecular structure (left) and mulliken charge distribution (right) of nicotinamide (NAM).
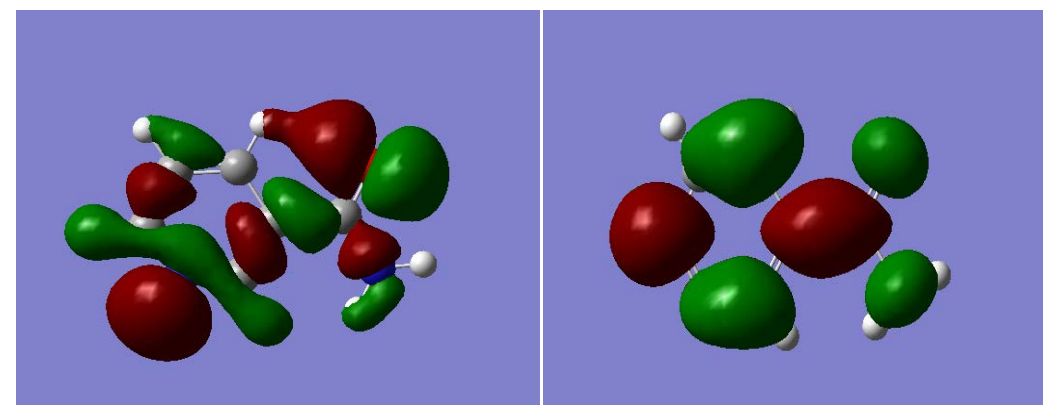

Figure 11. HOMO (left) and LUMO (right) Diagrams of Nicotinamide using B3LYP/6-31 + G (d, p). 
following atoms: oxygen, nitrogen and carbon atoms of the Pyridine ring, indicating that they are potential active centers for donor-acceptor interactions. The corrosion inhibition action of the molecule can be achieved via these adsorption centers [36].

HOMO energy is often associated with the ability of a molecule to give electrons, while LUMO energy indicates its ability to accept electrons. The binding capacity of the inhibitor to the metal surface [37] increases with increasing the HOMO value and decreasing the LUMO energy value. The quantitative parameters of quantum chemistry and reactivity are collected in Table 6 . The energy gap $\left(\Delta \mathrm{E}=\mathrm{E}_{\mathrm{LUMO}}-\mathrm{E}_{\mathrm{HOMO}}\right)$ is an important parameter as a function of reactivity of the inhibitor molecule towards the adsorption on the metallic surface. Lower values of the energy gap will render good inhibition efficiency, because the energy to remove an electron from the last occupied orbital will be low. In our case, the low value of $5.5294 \mathrm{eV}$ when compared with that of many molecules in the literature could explained the good inhibition efficiency of nicotinamide [38].

It is known that the value of the dipole moment $(\mu)$ characteristic of the hydrophobicity of the molecule decreases when the efficiency of the inhibition increases, suggesting that the molecules whose dipole moment is weak will easily adsorb to the metal surface. Similar results can be found in the literature, although several authors state that the inhibitory efficiency increases with the increase values of the dipole moment. In fact, a review of the literature [39] reveals several irregularities in the case of the correlation between the dipole moment and the inhibitory efficiency. In general, there is no significant relationship between the value of the dipole moment and the inhibitory power of a molecule.

Global hardness $(\eta)$ and softness (S) are important molecular properties to measure molecular reactivity and selectivity. Generally, a huge energy gap is observed for a hard molecule and a small energy gap is observed for a soft molecule. Hence, the reactivity of soft molecules is higher than that of hard molecules because they could easily donate electrons to an acceptor. Based on the computed values of hardness $(2.7647 \mathrm{eV})$ andsoftness $\left(0.3620(\mathrm{eV})^{-1}\right)$ (Table 6) we can say that nicotinamide has small hardness and high softness values compared with many molecules in the literature [32] [40].

Table 6. Quantum chemical descriptors for nicotinamide (NAM).

\begin{tabular}{cccc}
\hline Parameters & Values & Parameters & Values \\
\hline $\mathrm{E}_{\text {HОмо }}(\mathrm{eV})$ & -7.3408 & $\mathrm{~A}(\mathrm{eV})$ & 1.8115 \\
$\mathrm{E}_{\mathrm{LUMO}}(\mathrm{eV})$ & -1.8115 & $\chi(\mathrm{eV})$ & 4.5762 \\
$\Delta \mathrm{E}(\mathrm{eV})$ & 5.5293 & $\Delta \mathrm{N}$ & -0.0181 \\
$\mu(\mathrm{D})$ & 1.4863 & $\eta(\mathrm{eV})$ & 2.7647 \\
$\mathrm{I}(\mathrm{eV})$ & 7.3408 & $\mathrm{~S}(\mathrm{eV})$ & 0.3620 \\
$\mathrm{w}(\mathrm{eV})$ & 3.7860 & $\Delta \mathrm{E}_{\mathrm{T}}(\mathrm{eV})$ & -0.6912 \\
\hline
\end{tabular}


The absolute electrophilicity index was also calculated. According to the definition, this index measures the propensity of chemical species to accept electrons. A high value of electrophilicity index [41] describes a good electrophile while a small value of electrophilicity index denotes a good nucleophile. This reactivity index measures the stabilization in energy when the system acquires an additional electronic charge from the environment. The obtained value ( $\omega=$ 3.786) shows that the inhibitor is an electrophile molecule: it can receive electrons.

Negative sign of total energy change $\left(\Delta \mathrm{E}_{\mathrm{T}}=-\mathbf{0 . 6 9 1 2 \mathrm { eV }}\right)$ shows that the charge transfer to the molecule followed by backdonation from the molecule is energetically favorable (charge transfer to the molecule and backdonation from the molecule). Similar observation has been reported in the literature [32].

The parameter $\Delta \mathrm{N}$, the number of electrons transferred, also known as the ability to exchange electrons, indicates the tendency of a molecule to give electrons to the metal surface if $\Delta \mathrm{N}>0$ and the opposite if $\Delta \mathrm{N}<0$ [42]. In our case the obtained value of $\Delta \mathrm{N}(-\mathbf{0 . 0 1 8 1})$ shows that the inhibition efficiency results from electrons acceptance.

\subsubsection{Local Parameters}

Prediction of local selectivity such as condensed Fukui functions $[f(\boldsymbol{r})]$ and condensed local softness $[s(\boldsymbol{r})]$ indices can provide a chemical insight into atoms that have a significant tendency toward donation or acceptance of whole or fraction of electrons [43]. In this method the chemical reactivity of inhibitors can be evaluated for each atom. The nucleophilic $\left(\mathrm{f}^{+}\right)$and electrophilic $\left(\mathrm{f}^{-}\right)$Fukui functions can be calculated using the finite difference approximation as follows [38]:

$$
\begin{array}{r}
f_{k}^{+}=q_{k}(N+1)-q_{k}(N) \\
f_{k}^{-}=q_{k}(N)-q_{k}(N-1)
\end{array}
$$

where $q_{k}$ represents the atomic charge of atom k. $q_{k}(N+1), q_{k}(N)$ and qk $q_{k}(N-1)$ are the charges of the atoms on the systems with $(\mathrm{N}+1), \mathrm{N}$ and $(\mathrm{N}-$ 1) electrons, respectively. Condensed softness indices $\left(s^{ \pm}\right)$of the molecules can be calculated from the following relation between global softness (s) and condensed Fukui function $\left(f^{ \pm}\right)[40]$.

$$
\begin{aligned}
& s_{k}^{+}=f_{k}^{+} \cdot S \\
& s_{k}^{-}=f_{k}^{-} \cdot S
\end{aligned}
$$

The calculated nucleophilic $\left(\mathrm{f}^{+}\right)$and electrophilic $\left(\mathrm{f}^{-}\right)$condensed Fukui functions are listed in Table 7 for non-hydrogen atoms.

The preferred site for nucleophilic attack is the atom in the molecule where the value of $f_{k}^{+}$is maximum and it is associated with the LUMO region while the site for electrophilic attack is controlled by the values of $f_{k}^{-}$which is associated with the HOMO region. In NAM, the highest $f_{k}^{+}$value was found at $\mathrm{C}(5)$ atom with $\mathbf{0 . 0 5 8 7 7 6}$ indicating that $\mathrm{C}(5)$ is the prefered site for nucleophilic 
Table 7. Condensed fukui function and local softness values of NAM.

\begin{tabular}{cccccccc}
\hline Atome & $\mathrm{q}(\mathrm{N}+1)$ & $\mathrm{q}(\mathrm{N})$ & $\mathrm{q}(\mathrm{N}-1)$ & $\mathrm{f}^{+}$ & $\mathrm{f}^{-}$ & $\mathrm{s}^{+}$ & $\mathrm{s}^{-}$ \\
\hline $\mathrm{C}(1)$ & -0.338637 & -0.187616 & -0.175021 & -0.151021 & -0.012595 & -0.0546696 & -0.00455939 \\
$\mathrm{C}(2)$ & 0.002553 & 0.088528 & 0.143827 & -0.085975 & -0.055299 & -0.03112295 & -0.02001824 \\
$\mathrm{C}(3)$ & -0.164989 & -0.034904 & 0.140229 & -0.130085 & -0.175133 & -0.04709077 & -0.06339815 \\
$\mathrm{C}(3)$ & 0.427062 & 0.492693 & 0.23178 & -0.065631 & 0.260913 & -0.02375842 & 0.09445051 \\
$\mathrm{C}(5)$ & -0.382785 & -0.441561 & -0.331454 & 0.058776 & -0.110107 & 0.02127691 & -0.03985873 \\
$\mathrm{~N}(6)$ & -0.245746 & -0.15164 & 0.058781 & -0.094106 & -0.210421 & -0.03406637 & -0.0761724 \\
$\mathrm{C}(11)$ & 0.052124 & 0.176383 & 0.177515 & -0.124259 & -0.001132 & -0.04498176 & -0.00040978 \\
$\mathrm{O}(12)$ & -0.653813 & -0.550277 & -0.285117 & -0.103536 & -0.26516 & -0.03748003 & -0.09598792 \\
$\mathrm{~N}(13)$ & -0.583542 & -0.555658 & -0.49591 & -0.027884 & -0.059748 & -0.01009401 & -0.02162878 \\
\hline
\end{tabular}

attack and The atom $\mathrm{C}(3)$ is the preferred site for electrophilic attack since this atom has the highest value of Fukui function $f_{k}^{-} \quad(0.260913)$.

\section{Conclusions}

With nicotinamide (NAM), the corrosion of copper in $3.5 \% \mathrm{NaCl}$ solution is effectively reduced. The inhibition efficiency increases with increasing the concentration of NAM to reach a maximum value of $80 \%$ at a concentration of 10 $\mathrm{mM}$ but decreases as the temperature increases. Potentiodynamic polarization curves have indicated that this molecule acts as a mixed type inhibitor. The adsorption of the NAM on the surface of the copper is carried out by physical adsorption mechanism and according to the Langmuir adsorption isotherm model.

The linear polarization gave us to note that the polarization resistance $R_{P}$ decreases with the immersion time indicating that the protective layer formed on the surface of the metal cannot protect it durably. Raman spectroscopy investigation confirmed that the inhibition of copper corrosion is achieved by adsorption of NAM molecules onto its surface forming a complex with $\mathrm{Cu}^{+}$ions and preventing the formation of chloride complexes $\left(\mathrm{CuCl}_{2}^{-}\right)$.The morphology of the specimen surface is provided by optic microscopy. It can be seen general corrosion in $\mathrm{NaCl} 3.5 \%$ alone but pitting copper corrosion in with NAM. There is a fairly good agreement between the calculated electronic and global reactivity parameters of NAM and the experimental results. Reactive sites for nucleophilic and electrophilic attacks were indicated using the Fukui functions. The electrochemical impedance spectroscopy could be used to evaluate again the protective behavior of NAM film by determining parameters such as charge transfer resistance and double layer capacitance. The synergistic effect of the mixture of NAM and NAC (nicotinic acid) will also be studied.

\section{Acknowledgements}

The authors express great thanks to professor Juan Creus for allowing the achievement of this research in his laboratory. 


\section{References}

[1] Nunez, L., Reguera, E., Corvo, F., et al. (2005) Corrosion of Copper in Seawater and Its Aerosols in a Tropical Island. Corrosion Science, 47, 461-484. https://doi.org/10.1016/j.corsci.2004.05.015

[2] Khaled, K. (2008) Application of Electrochemical Frequency Modulation for Monitoring Corrosion and Corrosion Inhibition of Iron by Some Indole Derivatives in Molar Hydrochloric Acid. Materials Chemistry and Physics, 112, 290-300. https://doi.org/10.1016/j.matchemphys.2008.05.056

[3] Alar, V., Stojanović, I., Židov, B., et al. (2013) Corrosion Resistance of High Alloyed Materials in $3.5 \% \mathrm{NaCl}$ Solution at Elevated Temperature. International Journal of Electrochemical Science, 8, 12476-12486.

[4] Arenas, M., Bethencourt, M., Botana, F., et al. (2001) Inhibition of 5083 Aluminium Alloy and Galvanised Steel by Lanthanide Salts. Corrosion Science, 43, 157-170. https://doi.org/10.1016/S0010-938X(00)00051-2

[5] Bethencourt, M., Botana, F., Calvino, J., et al. (1998) Lanthanide Compounds as Environmentally-Friendly Corrosion Inhibitors of Aluminium Alloys: A Review. Corrosion Science, 40, 1803-1819. https://doi.org/10.1016/S0010-938X(98)00077-8

[6] Chidiebere, M.A., Oguzie, E.E., Liu, L., et al. (2015) Adsorption and Corrosion Inhibiting Effect of Riboflavin on Q235 Mild Steel Corrosion in Acidic Environments. Materials Chemistry and Physics, 156, 95-104. https://doi.org/10.1016/j.matchemphys.2015.02.031

[7] Ahmed, R.A. (2016) Investigation of Corrosion Inhibition of Vitamins B1 and C on Mild Steel in $0.5 \mathrm{M} \mathrm{HCl} \mathrm{Solution:} \mathrm{Experimental} \mathrm{and} \mathrm{Computational} \mathrm{Approach.}$ Oriental Journal of Chemistry, 32, 295-304. https://doi.org/10.13005/ojc/320133

[8] Fuchs-Godec, R. and Zerjav, G. (2015) Corrosion Resistance of High-Level Hydrophobic Layers in Combination with Vitamin E-( $\alpha$-tocopherol) as Green inhibitor. Corrosion Science, 97, 7-16. https://doi.org/10.1016/j.corsci.2015.03.016

[9] Tüken, T., Yazici, B. and Erbİl, M. (2002) The Effect of Nicotinamide on Iron Corrosion in Chloride Solutions. Turkish Journal of Chemistry, 26, 735-742.

[10] Branzoi, F. and Branzoi, V. (2014) Adsorption and Inhibitive Corrosion Properties of Nicotinamide on Carbon Steel in Colling Water Systems. Revue roumaine de chimie, 59, 299-310.

[11] Frisch, M., Trucks, G., Schlegel, H., et al. (2003) Gaussian 03, Revision A. 1. Gaussian Inc., Pittsburgh.

[12] Jiménez, Y.S., Gil, M.T., Guerra, M.T., et al. (2009) Interpretation of Open Circuit Potential of Two Titanium Alloys for a Long Time Immersion in Physiological Fluid. Bulletin of the Transilvania University of Braşov, 2, 51.

[13] Curkovic, H.O., Stupnisek-Lisac, E. and Takenouti, H. (2010) The Influence of pH Value on the Efficiency of Imidazole Based Corrosion Inhibitors of Copper. Corrosion Science, 52, 398-405. https://doi.org/10.1016/j.corsci.2009.09.026

[14] Otmačić, H. and Stupnišek-Lisac, E. (2003) Copper Corrosion Inhibitors in Near Neutral Media. Electrochimica Acta, 48, 985-991.

https://doi.org/10.1016/S0013-4686(02)00811-3

[15] Selvi, S.T., Raman, V. and Rajendran, N. (2003) Corrosion Inhibition of Mild Steel by Benzotriazole Derivatives in Acidic Medium. Journal of Applied Electrochemistry, 33, 1175-1182. https://doi.org/10.1023/B:JACH.0000003852.38068.3f

[16] Elhousni, L., Galai, M., Elkamraoui, F., et al. (2017) Corrosion and Scale Studies of Copper Used in Moroccan Industrial Cooling Water Systems. Euro-Mediterranean 
Journal for Environmental Integration, 2, 12. https://doi.org/10.1007/s41207-017-0024-y

[17] Azaroual, M., El Harrak, E., Touir, R., et al. (2016) Synergistic Corrosion Protection for Galvanized Steel in 3.0\% NaCl Solution by Sodium Gluconate and Cationic Surfactant. Journal of Molecular Liquids, 220, 549-557. https://doi.org/10.1016/j.molliq.2016.04.117

[18] Yadav, D.K. and Quraishi, M. (2012) Electrochemical Investigation of Substituted Pyranopyrazoles Adsorption on Mild Steel in Acid Solution. Industrial \& Engineering Chemistry Research, 51, 8194-8210. https://doi.org/10.1021/ie3002155

[19] Tazi, S., Raissouni, I., Chaoukat, F., et al. (2016) The Inhibition Effect of Brass Corrosion in $\mathrm{NaCl} 3 \%$ by Eugenol. Journal of Materials and Environmental Science, 7, 1642-1652.

[20] Gerengi, H., Ugras, H.I., Solomon, M.M., et al. (2016) Synergistic Corrosion Inhibition Effect of 1-ethyl-1-methylpyrrolidinium Tetrafluoroborate and Iodide Ions for Low Carbon Steel in $\mathrm{HCl}$ Solution. Journal of Adhesion Science and Technology, 30, 2383-2403. https://doi.org/10.1080/01694243.2016.1183407

[21] Villamil, R.F., Corio, P., Agostinho, S.M., et al. (1999) Effect of Sodium Dodecylsulfate on Copper Corrosion in Sulfuric Acid Media in the Absence and Presence of Benzotriazole. Journal of Electroanalytical Chemistry, 472, 112-119. https://doi.org/10.1016/S0022-0728(99)00267-3

[22] Vashi, R. and Champaneri, V. (1997) Toluidines as Corrosion Inhibitors for Zinc in Sulphamic Acid.

[23] Benali, O., Larabi, L., Tabti, B., et al. (2005) Influence of 1-methyl 2-mercapto Imidazole on Corrosion Inhibition of Carbon Steel in $0.5 \mathrm{M} \mathrm{H}_{2} \mathrm{SO}_{4}$. Anti-Corrosion Methods and Materials, 52, 280-285. https://doi.org/10.1108/00035590510615776

[24] Gomma, G.K. and Wahdan, M.H. (1995) Inhibition Action of n-decylamine on the Dissolution of Low Carbon Steel in Sulphuric Acid. IJCT, 2, 107-110.

[25] Obot, I., Obi-Egbedi, N. and Umoren, S. (2009) Antifungal Drugs as Corrosion Inhibitors for Aluminium in 0.1 M HCl. Corrosion Science, 51, 1868-1875. https://doi.org/10.1016/j.corsci.2009.05.017

[26] Szauer, T. and Brandt, A. (1981) Adsorption of Oleates of Various Amines on Iron in Acidic Solution. Electrochimica Acta, 26, 1253-1256. https://doi.org/10.1016/0013-4686(81)85107-9

[27] Li, X., Deng, S. and Fu, H. (2011) Benzyltrimethylammonium Iodide as a Corrosion Inhibitor for Steel in Phosphoric Acid Produced by Dihydrate Wet Method Process. Corrosion Science, 53, 664-670. https://doi.org/10.1016/j.corsci.2010.10.013

[28] Bolukbasi, O. and Akyuz, S. (2005) Computational Vibrational Study on Coordinated Nicotinamide. Journal of Molecular Structure, 744, 961-971.

https://doi.org/10.1016/j.molstruc.2004.11.056

[29] Bakiler, M., Bolukbasi, O. and Yilmaz, A. (2007) An Experimental and Theoretical Study of Vibrational Spectra of Picolinamide, Nicotinamide, and Isonicotinamide. Journal of Molecular Structure, 826, 6-16. https://doi.org/10.1016/j.molstruc.2006.04.021

[30] Pal, T., Narayanan, V.A., Stokes, D., et al. (1998) Surface-Enhanced Raman Detection of Nicotinamide in Vitamin Tablets. Analytica Chimica Acta, 368, 21-28. https://doi.org/10.1016/S0003-2670(98)00192-5

[31] Soliman, S.M. and Massoud, R.A. (2012) Theoretical Studies of Molecular Structure and Vibrational Spectra of Free, H-Bonded and Coordinated Nicotinamide. Com- 
putational and Theoretical Chemistry, 988, 27-33.

https://doi.org/10.1016/j.comptc.2012.02.022

[32] Niamien, P., Kouassi, H., Trokourey, A., et al. (2012) Copper Corrosion Inhibition in $1 \mathrm{M} \mathrm{HNO}_{3}$ by Two Benzimidazole Derivatives. International Scholarly Research Network (ISRN) Materials Science, 2012, Article ID: 623754.

https://doi.org/10.5402/2012/623754

[33] El Ibrahimi, B., Soumoue, A., Jmiai, A., et al. (2016) Computational Study of Some Triazole Derivatives (un-and Protonated Forms) and Their Copper Complexes in Corrosion Inhibition Process. Journal of Molecular Structure, 1125, 93-102. https://doi.org/10.1016/j.molstruc.2016.06.057

[34] Li, W., He, Q., Pei, C., et al. (2007) Experimental and Theoretical Investigation of the Adsorption Behaviour of New Triazole Derivatives as Inhibitors for Mild Steel Corrosion in Acid Media. Electrochimica Acta, 52, 6386-6394.

https://doi.org/10.1016/j.electacta.2007.04.077

[35] Özcan, M., Dehri, I. and Erbil, M. (2004) Organic Sulphur-Containing Compounds as Corrosion Inhibitors for Mild Steel in Acidic Media: Correlation between Inhibition Efficiency and Chemical Structure. Applied Surface Science, 236, 155-164. https://doi.org/10.1016/j.apsusc.2004.04.017

[36] Martinez, S. and Štagljar, I. (2003) Correlation between the Molecular Structure and the Corrosion Inhimition Efficiency of Chestnut Tannin in Acidic Solutions. Journal of Molecular Structure: Theochem, 640, 167-174. https://doi.org/10.1016/j.theochem.2003.08.126

[37] Popova, A., Christov, M. and Deligeorgiev, T. (2003) Influence of the Molecular Structure on the Inhibitor Properties of Benzimidazole Derivatives on Mild Steel Corrosion in 1M Hydrochloric Acid. Corrosion, 59, 756-764. https://doi.org/10.5006/1.3277604

[38] Jeeva, M., Prabhu, G.V. and Rajesh, C. (2017) Inhibition Effect of Nicotinamide and Its Mannich Base Derivatives on Mild Steel Corrosion in HCl. Journal of Materials Science, 52, 12861-12888. https://doi.org/10.1007/s10853-017-1401-2

[39] Khaled, K., Babić-Samardžija, K. and Hackerman, N. (2005) Theoretical Study of the Structural Effects of Polymethylene Amines on Corrosion Inhibition of Iron in Acid Solutions. Electrochimica Acta, 50, 2515-2520. https://doi.org/10.1016/j.electacta.2004.10.079

[40] Kouakou, V., Niamien, P.M., Yapo, A.J., et al. (2016) Experimental and DFT Studies on the Behavior of Caffeine as Effective Corrosion Inhibitor of Copper in $1 \mathrm{M}$ $\mathrm{HNO}_{3}$. Orbital-The Electronic Journal of Chemistry, 8, 66-79. https://doi.org/10.17807/orbital.v8i2.804

[41] Parr, R.G., Szentpaly, L.V. and Liu, S. (1999) Electrophilicity Index. Journal of the American Chemical Society, 121, 1922-1924. https://doi.org/10.1021/ja983494x

[42] Petrović Mihajlović, M.B., Radovanović, M.B., Tasić, Ž.Z., et al. (2017) Imidazole Based Compounds as Copper Corrosion Inhibitors in Seawater. Journal of Molecular Liquids, 225, 127-136. https://doi.org/10.1016/j.molliq.2016.11.038

[43] Obot, I., Macdonald, D. and Gasem, Z. (2015) Density Functional Theory (DFT) as a Powerful Tool for Designing New Organic Corrosion Inhibitors. Part 1: An Overview. Corrosion Science, 99, 1-30. https://doi.org/10.1016/j.corsci.2015.01.037 